REFLECTIONS ON THE POSITION OF THE FOREST AND OF FORESTRY IN EUROPE

M. Van Miegroet

State University, Faculty of Agricultural Sciences, Department of General and Comparative Silviculture.

Research Centre for Silviculture, Forest Management and Forest Policy.

PLAN

TWO SCHOOLS OF THOUGHT

THE AREAS OF CONFLICT

THE REALITY OF DIVERSITY

THE PERSISTENCE OF CONTROVERSIAL OPINION

The time factor

The choice of species

The efficiency of management

The basis for planning

THE RECOGNITION OF FUTURE NEEDS

CONCLUSIONS 
The extremely well organized "13th International Forestry Students Symposium " ( Dublin; 3-5 january, 1985) provided an excellent opportunity to take stock of and evaluate the convictions, options and apprehensions of the coming generation of university educated foresters, who within a few years, will take over the care for and the management of the European forest.

It was a refreshing experience to witness the deliberation, conducted on a high level of competence and concern. Euqally striking was the willingness of all participants to listen to each other, as well as their endeavour to express their opinions with clarity, courtesy and comprehension.

All ingredients were present for an interesting analysis of the most evident aspects of forestry in Europe to-day. The areas of conflict were recognised, stress situations dissected, differences in outlook and approach clearly outlined, alternative solutions to actual problems explored and misgivings formulated concerning the potential consequences for the forest of present environmental deterioration.

It was equally intriguing to hear so frequently used and repeated terms such as : investor, investments, financing, financial returns, profit, efficiency, planning, linking present interests with the preoccupations of previous generations of foresters. It also indicates a certain continuity of concern and analysis, expressed by the approach to the main problems of forestry as recognised by forestry students.

\section{TWO SCHOOLS OF THOUGHT}

The persistence of two schools of thought in Europe must still be acknowledged. They are not really opposites, but, nevertheless, are recognisable by a different approach to the use and management of the forest, which reflects specific experiences and differences in historical background which induced their development.

They are not separated along a north-south line as suggested in newsletter 204 of the E.C. on "Europe's Green Mantle : Heritage and Future of our Forests ". It seems, in fact, more relevant to link differences in aim and practice with population-density, geo-climatological factors, economic conditions, cultural background and socio-political situations.

The centre of gravity of the more economic oriented school of forestry, alternatively designated as "artificial ", "commercial " or "monofunctional ", seems to reside in the U.K. and Scandinavia. A more ecological approach to forest management greatly conditioned by social circumstances, industrialisation and environmental preoccupations is typical for continental Europe from east to west, more spe- 
cifically for the sphere of influence of the Zürich-school of silviculture and its protagonists, $S \subset \mathrm{h} \ddot{a} \mathrm{~d} e \mathrm{l} \mathrm{i}$ and $\mathrm{L}$ e $i$ b u n d g u t. It is often characterised, although incorrectly, as "natural", "non-commercial " or " non-economic ".

The main points of distinction between both schools reside in a difference of conception with relation to

aims : $\quad$ maximal production vs sustained yield.

functionality: $\quad$ monofunctional vs. multifunctional forest, resulting from a different perception of the relative importance of material production and non-material services.

the choice of species : $\quad$ preference for fast growing conifers vs. need for mixed forests of hardwoods and conifers, mostly on account of the importance attributed to broadleaved species and their phytogeographical position.

The existence of both schools reflects a difference of opinion on the real signification and importance of the time-factor. They correspond to an unequal definition of the forest, as the object of forestry.

In greater parts of continental Europe the aims of forestry are directly determined by silvicultural preoccupations. They result from long experience and learning from errors and miscalculations, which are not to be repeated in the future. They have nothing to do with a romantic approach, are not the expression of a vague philosophy, but should be seen as a response to pressures, exerted by human society, which, in the end, determines what must be done with the forest.

In this respect the situation in the Netherlands and in Belgium proves that public interest in the forest, as well as the relative importance of the social forest function and the social position of the forester do not depend upon the absolute and actual extent of the forest area. The public interest is rather an emanation of the present need for outdoor recreation, the availability of leisure time, the growing demand for amenities, the increase of environmental stress and the concentration of highly mobile populations in overcrowded cities.

Although forest management, under all circumstances, must have sound economical and technical foundations, it is therefore unacceptable to elevate the necessity of financial profit to the rank of economic dogma, at least in the public forest. Mark A $n d$ e $r s$ on and others were right in considering the cost of afforestation as a 
social expenditure to correct the former misuse of the land. The same basic idea is applicable to some aspects of forestry in a broader sense.

As the most trenchant areas of conflict the Symposium of Dublin identified the relationship of forestry with agriculture and, to a lesser extent, landscaping. Competition between forestry and nature conservation was not acknowledged as a real problem, indicating a change of opinion, expressed by the younger generation, and a positive development in a situation, formerly stressed by diversified motivations and regrettable misunderstandings.

The relationship between forestry and agriculture is not identical in all European countries.

An extreme situation exists in Sweden, where the farmer is considered as the real backbone of forest management. Most farmers own some forest land, which they use, rather conservatively, as a real money box to be called upon in times of acute need.

An equally extreme but opposite situation is typical for Ireland, where the farmer is not interested at all in forest ownership and, consequently, considers all afforestations as an intrusion upon his rights and a misuse of much needed farmland. Although in this country the extension of the farm-forest is often declared to be a main line of official forest policy, its actual realisation is considered by many experts as belonging to the realm of wishfull thinking.

In the other European countries the relationship between agriculture and forestry is situated somewhere between these extremes, depending upon the importance of the forest area and the development and type of forest ownership by farmers. It proves, once again, that a north-south line of division in the conception of forestry and the use of the forest does not really exist.

On the other hand, it is evident that the confrontation between forestry and agriculture is fomented by misunderstandings and lack of information. Therefore it is necessary to explain the real nature of the forest in simple terms. At the same time, the dissimilarity between forest and tree plantation or tree farm must be stressed, letting it be known that forest management is not to be equated with tree cropping. Sound forest management rests on the recognition of the necessity and importance of sustained yield of products and services. It considers the tree crop as a consequence and not as the principal aim of forest treatment. 
Conflicting interests are nourished in many countries by the nearly senseless opposition of the notions of "farmland " and "forest land ". Both concepts do not concur with an ecological or even a sociological reality.

They are but the expression of an actual - temporal and local - type of land use, to be decided upon by legal and democratic procedure, aiming at a tenable equilibrium between individual and collective aspirations. Therefore the use of so-called agricultural land or farmland for forestry purposes is not to be considered as a one way process. The developments of land use in Europe at the end of the 30-years war, and after the period of famine in the later part of the 19th century, as well as the redistribution of land use following the end of world wars I and II prove this point.

The relationship between forestry and landscaping is less stressed. It is often related to divergencies of opinion concerning space scales and forms of land occupation. The negative effects of forest homogeneisation and of artificial afforestation following a strict space pattern in predominantly rural or agricultural areas are generally deplored by landscapers and in fact, most official forest services were not always fully aware of their responsibility in this field, although a number of possibilities for good landscaping at low cost and not opposed to current forestry practice are available, if the will to use them really exists.

A more harmonious positioning of the forest in the landscape in a broader sense does not require exceptionally high expenditures. It can be obtained by the correct choice of species, the promotion of mixtures ( species, age-classes, etc.) in different spatial and temporal combinations, the use of natural regeneration and the execution of thinnings with more than tree cropping in mind.

Landscaping is a social, humanistic and moral obligation, but it does not have to reach the level where it influences forest management negatively, a fear, often heard expressed in Scandinavian countries. After all, what is efficiency? Is it the realisation of maximal material production at minimal cost ? or is it the sustained production of the most diversified benefits for the greatest number at a level of cost and interference, acceptable to human society ?

\section{THE REALITY OF DIVERSITY}

The elaboration of basic guidelines for an acceptable forest policy in Europe, depends upon the will ingness to accept non-accidental differences, in view, aims, outlook and procedure, as they exist in different countries. Such differences are not a sign of weakness. Neither do they express a dispersion of effort. 
They stand, in fact, for some kind of pluralism, created by diversified historical developments, socio-cultural background and economic opportunities. tivity.

They are related to several fields of human interest and ac-

Management aims in some countries at polyvalent forests, accepting the variability of the relative importance of economic, ecological and social values. In others, where forestry has more direct ties with industry, the level of material production is thought to be of primordial and undisputable importance.

The role of the state in the regulation of forest production and ownership is also quite different : In some instances state intervention is complementary to private initiative, whereas in other countries it has a really preponderant, even dominating function in the organisation of forest use and management. Even the outlook on the state-owned forest can be different : We are told that in Ireland the state tries to sell its forests, but in Belgium the acquisition of more state forests is accepted as a fundamental principle of current forest policy.

Even cutting regulations can be fundamentally different : Most countries feel the need to define by law the maximal limits, in space and mass, of forest exploitation, but in Sweden minimal cutting levels are considered necessary.

Such variations in approach are not related to the growth rate of forests, as shown by the example of the mean annual increment of spruce in Sweden ( $1 \mathrm{~m}^{3} / \mathrm{yr} / \mathrm{ha}$ in the North) and Belgium ( at least $10-15 \mathrm{~m}^{3} / \mathrm{yr} / \mathrm{ha}$ with C.I. often attaining $>20 \mathrm{~m}^{3} / \mathrm{yr} / \mathrm{ha}$ ).

Curiously enough, tree growth is often considered as being too quick to satisfy production needs (Norway) and, alternatively, too slow (most other countries, but especially the U.K. ).

Equally significant is the variation in relationship between wood industries and agriculture on one side and forestry on the other.

In Sweden, Norway and Finland the direct link between forestry and industry is thought to be essential for the preservation of public welfare, but industrial development is considered as the main threat to forest survival and as highly detrimental to human well-being in the F.R.G. In Sweden the farmer is the backbone of forestry, but in Ireland its harshest ennemy.

Neither is there any uniformity of opinion on land use planning and its function. Somie Irish foresters complain that land use planning is inadequate in their country and insufficient in its effects because forests are excempt from the planning act. In Belgium, on the contrary, 
most forest owners consider land use planning as abusive and a real hindrance with many negative effects on forestry and on stability of forest ownership.

Even a superficial and incomplete inventory of essential differences in the organisation of forest use and the basic concepts of forestry in some European countries indicates that, at least provisionally, there is no need for a common European forest policy. It is questionable, indeed, whether such a policy could be formulated, agreed upon by all participants and applied consequently.

If there really should arise a need for the elaboration of a common European forest policy, it should have to be made from the bottom up as the workable integration of clearly formulated and executable lines of national forest policy, based upon the recognition of the relative value of the products and services, rendered by the forest. It should be the expression of the will and the determination for a harmonious development of those forest functions, which correspond best to general human ambition or are most suitable to national needs, public welfare and diversified interests.

To realise an integration in political conduct of this kind, some basic principles must be accepted by all parties : the need to protect the forest against irreversible perturbation, the desirability to extend the forest to areas where its presence is needed or beneficial and the necessity to develop forest functions, with a changing relative importance in time and space, on a pluralistic basis, aiming at an acceptable level of sustained yield of material production and desirable services.

THE PERSISTENCE OF CONTROVERSIAL OPINION

In a pluralistic society different and even controversial approaches are not only unavoidable, but they can, occasionally, become real innovators or are, at least, an incentive to creative thinking.

\section{The time factor}

One of the most controversial themes in European forestry is, undoubtly, the assessment and evaluation of the importance of time amply illustrated by never ending discussions on the optimal length of forest rotations.

"Time ", as used by the forester, is a vague and not fully worked out concept. It is often forgotten, that " time ", is not only a means to measure the distance between events, but also a working factor. 
It is good forest strategy to let time do its work and to use the change it generates to the best of our knowledge, abilities and evolving needs.

It is therefore advisable to project the choice of rotations against the life history and life expectancy of tree species, the need for forest stability and the subsequent promotion of tolerant species with a determinate growth pattern as essential elements of a conservative production strategy. Because of the acceleration of change in human society, it is, in fact, highly disputable whether actual economic requirements can be a good basis for the choice of the length of rotations. This also applies, and more specifically so, to the tropical world, where the danger for irreversible forest destabilisation is much greater than in Europe.

\section{The choice of species}

The choice of species must go out from their energetic efficiency and tolerance, their position in occupational succession (pioneers vs climax species ; early succession vs late succession species ) and the pattern of growth, ( determinate vs. indeterminate growth ). Surprisingly enough, the choice of species is in most cases still reduced to the choice between conifers and hardwoods.

The possibilities of such a choice are limited. They are further determined by invariable phytogeographical conditions and the variable prevalence of certain types of forest use.

Outside the natural area of dispersion of the conifers, hardwoods should be protected and promoted on all sites where they can grow and reproduce, in all cases where maximal forest stability in time and space is required and on all soils, where the maintenance of a high level of bio-ecological site productivity is possible or judged to be of primordial importance.

Broad-leaved species have a higher potential for the creation and maintenance of more complex and functional structuration, thus promoting forest stability, due to their evolutive history, grow patterns and longevity. Because of their variety and characteristics they are important components of numerous food chains thereby favouring the complexity of the ecosystem to which they belong, and answering the need for ecological stability, as well as for the conservation of floristic and faunistic resources, required ever more insistently by a considerable and increasing portion of human society.

Hardwoods can warrant sustained yield of a wide range of services and products. By their phenological aspects they influence the dynamic aspects of the landscape profoundly. The transformation of their timber not only allows a high valorisation level, but warrants also the survival of labour-intensive furniture industries. 
The argument that hardwood species require long rotations is irrelevant.

If hardwoods are present in the forest, they must be maintained because they follow their appropriate time patterns without any prejudice toward value production. If hardwood forests are to be created, the operation, quite evidently, takes time. This however is unimportant on a larger time scale and not a sound reason to maintain less-stabilised forest systems.

\section{The efficiency of management} cept.

Efficiency in forest management remains a much discussed con-

Some foresters measure efficiency by the level of economic production, financial rentability and reduction of labour input. Consequently they direct forest management toward homogeneous stands, preferably of conifers, shortened rotations and clearcutting, followed by artificial reforestation with selected materials. Such a procedure must ultimately result in the promotion, when and where possible, of short-lived clonal plantations.

Otherwise orientated silviculturists, contest this kind of management on various grounds.

They point out that net financial gain in forestry is no longer realisable in densely populated countries with restricted forest reserves, high labour-costs and considerable social expenditures. Thus the value of social service, health care and environmental stability, promoted or produced by the forest, surpasses, since many decades, the value of material production in the F.R.G., Belgium and the Netherlands.

On the other hand, it is unfair and unadequate to consider reduction of labour input as a measure for efficiency in countries where unemployment, particularly of the younger generation, is the main actual problem.

Therefore it is thought that the efficiency of forest management is to be measured by the level of satisfaction of different human needs in a variety of fields. To this end management is more directed toward the creation and maintenance of structural and functional forest stability, generating new problems, related to forest ownership and the controversial interests of individuals and the collectivity.

The basis for planning

Differences in opinion on the choice of species and rotation, the real significance of financial and social returns, the relative importance of economic and ecological values, the existence of two schools of thought in silviculture, create basically different conditions for 
the planning of forest management and forest use.

Some view actual wood consumption, the evolution of supply and demand, the level of financial profit as the sole acceptable basis for forest planning. Such a position is logical and understandable in countries such as Sweden, where the wood industries are the backbone of the national economy. It is however, less indicated for densely populated industrial countries with a low forest index, where national wood consumption can never be met by national wood production. In such countries the changes in forest use, wood transformation and consumption are more deeply felt as in those where a great portion of wood products ultimately reaches the international markets.

It therefore seems more adequate to direct forestry planning progressively toward the kind of human society wanted or expected. The participation of forest management in the creation and protection of social stability through the promotion of ecological stability and the relief of environmental stress, is of growing importance to a human society, in permanent evolution and subject to the acceleration of change.

\section{THE REGOGNITION OF FUTURE NEEDS}

The analysis of past and present forest situations results in the acknowledgment by the younger generation of the needs for better relations between the forest services and the public at large to take advantage of the growing awareness of ecological and environmental problems. The dying forest and the impact of acid rain in Germany are increasingly perceived as symbols for a disturbed relationship between man and nature. The average citizen is willing to pay the price for the restoration of the lost or endangered equilibrium. He will entrust the defense of his interests to the persons and services, who are listening and responding to his complaints. In this respect forestry can learn from industry and finance, who value public relations highly.

It is equally important to develop the social forest functions in several directions. Better spreading of forests and suitable afforestations can help to alleviate the pressure of unemployment. They can help in the organisation of better use of an increasing amount of leisure time by an growing number of citizens with variable abilities and belonging to different age-classes.

An impediment to such a worthy task is the actual tendency toward increasing mechanisation of forest labour, with restriction of job opportunities as a direct consequence.

Nevertheless, it is generally recognised that more attention should be paid to the social aspects of forest management. For this 
reason the absence of the study of social and political sciences is considered as the main lack in forest education on different levels.

On the other hand there is a growing consciousness that investments of the state in forestry must be interpreted as corrections of the errors of the past, also concerning the misuse of lands and nature. Forestry is considered, more and more, as a public service. Such an acceptance implies the rejection of profit as economic dogma and sole parameter for success.

It also requires deblocking of the minds of some land and forest owners, who, traditionally, do not appreciate the intervention of public authorities to protect the interests of the populations at large.

The elaboration, development and execution of a rightful forest policy aiming at the production of maximal benefits for the greatest number, stresses the value and importance of correct information and responsible evaluation of all tendencies and evolutions. Above all, it requires a fair amount of political will to make the right decision at the right time.

\section{CONCLUSIONS}

The thoroughness of the analyses and evaluations of actual problems and tendencies, directly or indirectly related to forestry, as done at the Dublin Symposium permits the conclusion that the future of the European forest is in good hands.

In discussions between young foresters a remarkable positive tone prevails, generated by the willingness to listen to each other and the readiness to accept responsibility.

The acute need to find acceptable solutions to a growing number of problems connected with the forest, its use and its sustained yield at a high level of material production and diverse services, neccesitates the deepening of knowledge in many fields, the improvement of forest education and a continuity of approach to be obtained by better understanding of human needs.

It is hopeful and reassuring that young foresters are ready to accept the task to create a more solid basis for their profession and to treat the forest in such a way that it will be most profitable to all human society. 
